\title{
Food-dependent, exercise-induced gastrointestinal distress
}

\author{
Erick Prado de Oliveira ${ }^{1,2^{*}}$ and Roberto Carlos Burini ${ }^{1}$
}

\begin{abstract}
Among athletes strenuous exercise, dehydration and gastric emptying (GE) delay are the main causes of gastrointestinal (Gl) complaints, whereas gut ischemia is the main cause of their nausea, vomiting, abdominal pain and (blood) diarrhea. Additionally any factor that limits sweat evaporation, such as a hot and humid environment and/or body dehydration, has profound effects on muscle glycogen depletion and risk for heat illness. A serious underperfusion of the gut often leads to mucosal damage and enhanced permeability so as to hide blood loss, microbiota invasion (or endotoxemia) and food-born allergen absorption (with anaphylaxis). The goal of exercise rehydration is to intake more fluid orally than what is being lost in sweat. Sports drinks provide the addition of sodium and carbohydrates to assist with intestinal absorption of water and muscle-glycogen replenishment, respectively. However GE is proportionally slowed by carbohydrate-rich (hyperosmolar) solutions. On the other hand, in order to prevent hyponatremia, avoiding overhydration is recommended. Caregiver's responsibility would be to inform athletes about potential dangers of drinking too much water and also advise them to refrain from using hypertonic fluid replacements.
\end{abstract}

Keywords: diet, gastrointestinal distress, physical exercise

\section{Introduction}

The importance of physical activity to well-being cannot be overstated. The physiological, psychological, and social benefits of regular exercise are plentiful and profound. Examples of such benefits include positive effects on weight, bone strength, metabolic factors (such as glucose and cholesterol), organ function, sleep, mood and self-image. Coupled with the proliferation of team sports and increased choices for individual exercise, the fitness movement has created an increased demand for the care of athletes. Anyone who participates in physical exercise is at risk for injury and illness arising from such activity $[1,2]$.

Strenuous exercise and dehydrated states would be the causes of gastrointestinal symptoms. Gut ischemia would be the main cause of nausea, vomiting, abdominal pain and (bloody) diarrhea [3]. Moreover, anaphylaxis is observed during or soon after exercise when preceded by the intake of a causal food allergen $[4,5]$. Adequate

\footnotetext{
* Correspondence: erick_po@yahoo.com.br

${ }^{1}$ Centre for Physical Exercise and Nutrition Metabolism, UNESP School of Medicine, Public Health Department, Botucatu City, São Paulo State, Brazil Full list of author information is available at the end of the article
}

meal composition and hydration are essential for the prevention of these events.

\section{Exercise-induced gastrointestinal complaints}

There is a very high prevalence of gastrointestinal (GI) complaints during exercise among long-distance runners, triathletes and athletes involved in other types of strenuous long-lasting exercise [6]. These GI complaints occur because of the redistribution of the blood flow, that is shunted from the viscera to skeletal muscle, heart, lung and brain [7].

The symptoms include dizziness, nausea, stomach or intestinal clamps, vomiting and diarrhea. Prevalence of 30-50\% has been reported among marathon runners. Severe symptoms include vomiting and diarrhea and occur mainly during running [8]. It has been suggested that these problems occur mainly because of the movements of the gut [9]. However, an association was reported between nutritional practices and GI complaints during a half ironman-distance triathlon with the intake of fiber, fat, protein and concentrated carbohydrate solutions during the triathlon, in particular beverages with very high osmolarity [10].

\section{() Biomed Central}


The symptoms are often mild and may not even affect performance. Some of the symptoms, however, can be life-threatening, such as blood loss in feces in the hours following the running presented by some marathoners and long-distance triathletes [8].

Damage to the gut and impaired gut function is associated with increased of intestinal permeability after a marathon [11]. Moreover, vigorous exercise (jogging, aerobics, dancing, tennis, bicycling, racquetball, swimming, and skiing) [12,13] facilities allergen absorption from the GI tract [14], leading to a food-dependent exercise induces anaphylaxis (FDEIA).

FDEIA is a subtype of anaphylaxis induced by exercise that is related to the intake of specific foods [15]. Allergic symptoms are elicited when triggering factors such as exercise or aspirin intake are added after intake of the causative food [16]. FDEIA is a unique disorder caused by exercise after food ingestion [17].

Ingestion of aspirin combined with exercise increased GI permeability in humans, thus allowing for the detection of food-derived allergens in serum [5]. When food intake and exercise are exposed independently, patients will not experience allergic symptoms [14]. However, the onset of anaphylaxis occurs during or soon after exercise when preceded by the ingestion of a causal food allergen $[4,5]$.

FDEIA is an IgE-mediated hypersensitivity. As in other allergic syndromes, mast cells seem to play a prominent role, and most FDEIA symptoms can be explained based on the release of mast cell mediators, including histamine, leukotrienes (LCT4), and prostaglandins (PGD2) $[14,16,18,19]$. Increased norepinephrine may be involved in the onset of FDEIA since it may selectively inhibit Thelper (Th) functions while favoring Th-2 responses [20].

Many kinds of food have been identified as causes of FDEIA, but any kind of food appears to be responsible for it. Specific FDEIA has been associated with cereals, seafood, peanut, free nuts, eggs, milk and vegetables [21]. FDEIA only occurs after consumption of a food allergen if this is followed by vigorous physical activity within a few hours of consumption [15]. Elicitation of the allergic symptoms is known to be dependent on the amount of the food intake [16]. FDEIA can be controlled by avoidance of food before exercise [13].

GI problems, hyperthermia and hyponatremia are potentially life-threatening in longer triathlon events. Problems with hyperthermia seem to be related to the intake of highly concentrated carbohydrate solutions, or hyperosmotic drinks, and the intake of fiber, fat and protein [8]. Hyponatremia has occasionally been reported, especially among slow competitors in triathlons, and probably arises from the loss of sodium in sweat in association with very high intake (8-10L) of water or other low-sodium drinks [8].

\section{Exercise-induced dehydration}

During exercise, activity in the sympathoadrenal neuroendocrine system and its plasma hormones increases. Such increase is of major importance for cardiovascular adaptation, thermoregulation and energy-yielding substrate in exercise. Cardiac frequency and contraction force are enhanced; the tone of arterioles in the splanchnic area, kidney and non-contracting muscles and veins is increased, and the spleen is brought to contract. In this way, cardiac output is enhanced, and blood volume and flow are redistributed in favor of the skin and the working muscle [22].

Prolonged exercise at high intensities leads to a quantitative redistribution of blood flow to the exercising muscle (exercise hyperthermia) in proportion to its energy demands of oxygen and substrates. Sympathoadrenal activity, however, reduces water and sodium loss during exercise by decreasing renal blood flow and changing its distribution by direct tubular effects. Moreover, it decreases potassium loss by facilitating its muscular uptake [22].

Blood flow to the skin is increased to facilitate heat dissipation, and sweating implies loss of water and electrolytes from the body. Dehydration of approximately 2$3 \%$ of body mass routinely occurs during intermittent high-intensity exercise, especially when the ambient temperature is high. Usually, thirst is triggered when the individual is already $5 \%$ dehydrated [23]. The dehydrated state can be worsened by catecholamine-induced thirst suppression [24].

Fluid loss results in decreasing circulatory blood volume, blood pressure, sweat production and stroke volume, as result, vascular resistance increase leading to a skin blood flow decreased, all of which impair heat dissipation. Heart rate rises to some additional 3-5 beats/minute for every $1 \%$ body weight loss due to dehydration [25].

Dehydration has a negative effect on endurance performance by increasing muscular glycogen degradation and plasma lactate levels and by causing cardiovascular drift and reduced ability to transport heat to the periphery for dissipation, thus resulting in increased core temperature [26].

\subsection{Exercise-dependent, dehydration-induced hyperthermia}

Heat production during exercise is 15-20 times greater than at rest, and it is sufficient to raise core body temperature by $1^{\circ} \mathrm{C}$ every 5 minutes if there are no thermoregulatory adjustments [25]. The body's multiple mechanisms for heat dissipation to prevent significant hyperthermia include conduction, convection, evaporation and radiation. As ambient temperature rises above $20^{\circ} \mathrm{C}$, the contributions of conduction, convection and 
particularly radiation, become increasingly insignificant with the bulk of the heat dissipation during exercise resulting from evaporation as sweat. In hot, dry conditions, evaporation may account for as much as $98 \%$ of dissipated heat. Sweat evaporation leads to dehydration, which increases body temperature [25].

Any factor that limits evaporation, such as high humidity or dehydration will have profound effects on physiological function, athletic performance, and risk for heat illness [27]. There are five common types of heat illness, the milder forms including heat edema, heat cramps, heat syncope, and heat exhaustion. The most severe form of heat illness is heat stroke [28].

The milder forms of heat illness are widely underreported and underdiagnosed [25]. The symptoms go from none to fatigue, mental confusion, nausea, and vomiting with the signs beginning with peripheral edema developing to muscular spasm, loss of consciousness, hypotension and elevated core temperature up to $40.5^{\circ} \mathrm{C}[25]$.

Heat stroke is defined as a condition in which body temperature is elevated to a level that causes damage to body tissues, giving rise to a characteristic clinical and pathological syndrome that affects multiple organs [29]. Distinguishing features of heat stroke are marked core body temperature elevations greater than $40.5^{\circ} \mathrm{C}$, failing sweating mechanisms, often complete cessation of sweating, and moderate to severe mental status impairment. It is a medical emergency in which total thermoregulatory failure will not reverse without external cooling measures and the mortality rates may exceed $10 \%[25]$.

\subsection{Exercise-dependent dehydration-induced ischemia}

Blood flow to central tissues (gut and liver) is reduced during exercise by almost $80 \%$, at $70 \%$ of $\mathrm{VO}_{2 \max }$ [7]. Such decreased splanchnic blood flow and oxygen supply may induce changes in nutrient absorption, motility and the mucosal integrity of the GI tract, resulting in GI complaints [30]. GI distress has been reported to be common among 30\%-50\% of endurance athletes, especially during marathons, triathlons and other endurance events. The symptoms seem to occur more often during competition in a warm environment [30] in the presence of systemic dehydration and lower plasma volume [8]. Long-lasting high-dose creatine supplementation (80 g/ day during four months) is reported to lead to acute renal failure when associated with exhausting strength exercises and related lower plasma volume [31]. However, few or no adverse effects are observed when taking the recommended dose of creatine (10 g/day) [32,33].

\subsubsection{Exercise-induced gastric emptying delay}

Gastric emptying (GE) is thought to be negatively affected as exercise intensities reach over $70 \% \mathrm{VO}_{2 \max }$ [34]. The presence of dehydration in strenuous exercise in cyclists was shown to induce significantly increased nausea, epigastric cramps and delay in gastric emptying. Gastric emptying (GE) was significantly associated with increase in exercise-induced nausea. Exercise by itself led to significant increase in plasma vasopressin and rectal temperature and significant decrease in plasma volume, irrespective of the dehydration state, but vasopressin concentration was significantly higher in dehydrated athletes. By adding dehydration to strenuous cycling, there was a delayed gastric emptying, but no differences in orocecal transit time, intestinal permeability or glucose uptake [30].

In an endurance running experiment, GI complaints were reported only with the dehydration exercise combination without any GI disturbances being reported by athletes in either exercise or dehydration test alone. Dehydration-exercise resulted in slower GE than in other two treatments with the effects of dehydration and exercise being additives in delayed GE. It was concluded that the higher prevalence of GI disturbances may be related to delayed GE caused by exerciseinduced dehydration and/or thermal effects [35].

\subsection{Exercise-dependent ischemia-induced GI distress}

Serious gut underperfusion often leads to shock-induced mucosal damage and invasion of gram-negative intestinal bacteria and/or their toxic constituents (endotoxins) into the blood circulation [36]. Elevated plasma endotoxin concentrations were found in $81 \%$ of ultramarathoners $(90 \mathrm{~km})$, with $2 \%$ presenting extremely high values [37].

Reduced GI blood flow induced by strenuous exercise makes the gut mucosa susceptible to ischemic injury, increases mucosa permeability and enhances hidden blood loss, as well as the translocation of protective microbiota and endotoxin generation. It is known that mucosal ischemia depletes cellular ATP leading to cell death and mucosal inflammation $[11,38]$. Hence, strenuous exercise and dehydration states would be the causes of GI symptoms reported by $70 \%$ of athletes, and gut ischemia would be the main cause of nausea, vomiting, abdominal pain and (blood) diarrhea [3].

In an extensive literature review using an evidencebased approach, the risk factors for exercise-induced GI tract symptoms were dehydration (body weight loss > $4 \%$ during or after exercise), being a female, younger age, high-intensity exercise, vertical impact sports and medicine use. Poor conditioning, dietary factors and previous abdominal surgery are risk factors with weak evidence that was not well supported [39].

\section{Exercise-dependent rehydration}

Rapid fluid delivery from beverages intake is the goal of oral rehydration solutions and sports drinks [40]. The 
goal of fluid intake is to consume more fluid orally than it is being lost in sweat. Extracellular fluid rehydration is best achieved with smaller fluid volumes and isotonic sodium solutions. Intracellular rehydration is best achieved with higher volumes and lower sodium (hypotonic) solutions. Hemodynamic responses (the optimization of cardiac output as estimated by heart rate and stroke volume) are similar with $100 \%$ or $150 \%$ fluid replacement and with hypotonic and isotonic solutions. The addition of sodium and carbohydrates assists with intestinal absorption of water and permits more efficient fluid replacement than water alone [2].

\subsection{Fluid volume}

The maximum rate of intestinal absorption is $0.5 \mathrm{~L} /$ hour when cycling at $85 \% \mathrm{VO}_{2 \max }$ [8]. It was estimated that $0.9 \mathrm{~L}$ remained in the stomach and intestine at the end of exercise, and subjects complained about abdominal fullness. The intake of large volumes may not be advantageous [8], because no enhance in performance is observed [41,42].

Fluid delivery during exercise represents the integration of GE and intestinal absorption. GE of liquids is regulated by the interaction of gastric volume and feedback inhibition, including nutrient-induced duodenal feedback. This occurs in such a way that the GE rate at any given moment represents the balance between feedback inhibition from the small intestine and the stimulatory effect of gastric volume. It is this balance that is responsible for the inverse relationship between beverage $\mathrm{CHO}$ content and GE rate [43].

Fluids empty from the stomach in an exponential manner with an initial rapid emptying phase. In fact, one of the major stimulants of GE is the volume in the stomach with a positive relationship between stomach volume and rate of emptying from the stomach. The absorption of water in the intestine is primarily passive, where water passes across the intestinal membrane due to an osmotic gradient [8].

\subsection{Fluid composition}

In order to determine the effect of osmolality on intestinal (duodenum and/or jejunum) fluid absorption of an orally fluid-replacement beverage intake containing $6 \%$ carbohydrate, Gisolfi et al (1998) [44] formulated groups of fluid replacement as hypo, iso or hypertonic with water as placebo. Fluid absorption was given during 85 min of cycling exercise $\left(63.3 \% \mathrm{VO}_{2 \max }\right)$ in a mild environment $\left(22^{\circ} \mathrm{C}\right)$. There were no differences between groups in GE, total fluid absorption, urine production or plasma volume variations. Water was absorbed faster from the duodenum than the jejunum. It was concluded that osmolality has only a modest effect on gastric emptying and that total fluid absorption of $6 \% \mathrm{CHO}$ - beverage from the duodenum/jejunum during exercise, within 197-414 osmotic range, is not different from that of water.

The effectiveness of different carbohydrate solutions in restoring fluid balance in situations of voluntary fluid intake was examined in $1.99 \%$ body mass dehydrated (intermittent route) subjects [26]. Beginning $30 \mathrm{~min}$ after cessation of exercise, the subjects drank ad libitum for a period of 120 minutes. Drinks contained $31 \mathrm{mmol} /$ $\mathrm{L}$ sodium as $\mathrm{NaCl}$ and either $0 \%$, or $2 \%$ or $10 \%$ glucose, with osmolality of 74,188 and $654 \mathrm{mosm} / \mathrm{kg}$ respectively. No differences were observed in total fluid intake, urine output, net fluid balance or in the fraction of the drink intake retained. The authors concluded that in situations of voluntary fluid intake, hypertonic carbohydrate-electrolyte solutions are as effective as hypotonic carbohydrate-electrolyte solutions at restoring whole-body fluid balance [26].

Glucose is actively transported across the intestinal membrane, a process aided by the inclusion of sodium. Water co-transportation during this process is controversial; nevertheless, the addition of sodium and $\mathrm{CHO}$ to sports drinks is widely recommended to enhance water absorption [8]. The risks of exercise-induced fluid and electrolyte balance are considerably minimized if oral replacement products are used. If activity is prolonged beyond 60 minutes, then $\mathrm{CHO}$ sources and potassium should also be included in the ingested fluid [2].

During competition, optimal $\mathrm{CHO}$ concentration seems to be in the range of $5-8 \%$, and athletes should aim to achieve a $\mathrm{CHO}$ intake of 60-70 g/hour. Athletes should attempt to limit body mass loss to $1 \%$ of body mass. In all cases, a drink should contain sodium (30-50 $\mathrm{mmol} / \mathrm{L}$ ) for optimal absorption and hyponatremia prevention. Post-exercise rehydration is best achieved by consuming beverages that have high sodium content ( $>60 \mathrm{mmol}$ ) in a volume equivalent to $150 \%$ of body mass loss [8].

There is convincing evidence that the limitation of $1.0-1.1 \mathrm{~g} /$ minute $\mathrm{CHO}$ oxidation is not at the muscular level, but most likely located in the intestine or the liver. Intestinal perfusion studies suggest that the capacity to absorb glucose is only slightly in excess of the observed entrance of glucose into the blood, and the absorption rate may thus be a factor that contributes to the limitations. The liver, however, may play an additional important role in that it provides glucose to the blood stream at a rate of only $1.0-1.3 \mathrm{~g} / \mathrm{min}$ by balancing glucose from the gut and from glycogenolysis/gluconeogenesis. It is possible that when large amounts of glucose are ingested, absorption is a limiting factor, and the liver will retain some glucose and will thus act as a second limiting factor to exogenous $\mathrm{CHO}$ oxidation [8]. 
More recently, advice has been given for athletes engaged in moderate- intensity prolonged exercise to increase $\mathrm{CHO}$ intake in the form of multiple transportable carbohydrates (glucose plus fructose) to a rate as high as $90 \mathrm{~g} /$ hour (or $1.5 \mathrm{~g} / \mathrm{min}$ ), and this has been shown to increase exogenous $\mathrm{CHO}$ oxidation above a single $\mathrm{CHO}$ [43]. Furthermore, the intake of a glucosefructose combined solution increases GE and fluid delivery when compared with a glucose-only solution. Additionally, the combined sugar attenuates heart-rate increase and results in lower rates of perceived exertion and lower loss of body weight than glucose alone or water [43]. Moreover, a solution intake with $1.2 \mathrm{~g} / \mathrm{min}$ of maltodextrin $+0.6 \mathrm{~g} / \mathrm{min}$ of fructose show higher carbohydrate oxidation (approximately $1.5 \mathrm{~g} / \mathrm{min}$ ) than 1.8 $\mathrm{g} / \mathrm{min}$ of maltodextrin (alone) [45].

The effects of increasing carbohydrate $(0 \%, 3 \%, 6 \%$ and $9 \%)$ and sodium $(0,20,40,60 \mathrm{mmol} / \mathrm{L})$ content upon fluid delivery (using deuterium oxide water) were studied in healthy male seated (twenty-four) subjects. It was concluded that increasing the amount of sodium in a $6 \%$ glucose beverage did not lead to increases in fluid delivery and that fluid delivery was compromised when the carbohydrate beverage was increased above 6\% [40].

When glucose is used as the $\mathrm{CHO}$ source, its concentration is limited to $<2.5 \%$ since higher concentrations may delay GE and fluid absorption. In general, the combination of different $\mathrm{CHO}$ sources should be $>5 \%$ to provide sufficient fuel for the maintenance of muscle performance during activity. However, total $\mathrm{CHO}$ concentrations are limited to $<10 \%$ since higher $\mathrm{CHO}$ content is associated with increased risk for GI distress (abdominal cramps, diarrhea and nausea) owing to the high osmolar load [2]. Hypertonic solutions tend to delay water absorption in the intestine as water instead flows into the intestine to dilute the solution before water is absorbed [8].

Additionally, there is contention as to whether hypertonic solutions reduce the GE rate [46]. However, energy density is considered to be more important in determining GE when solutions with an osmolality close to those normally found in sports drinks are used [8].

The rate of fluid absorptions is closely related to the $\mathrm{CHO}$ content of drinks with high $\mathrm{CHO}$ concentrations, thus compromising fluid delivery. Hence, a balance must be met between the goal of maintaining hydration status and providing $\mathrm{CHO}$ to the working muscle [8]. Slowed gastric emptying associated with high-intensity exercise is further slowed by the consumption of hypertonic carbohydrate beverages, usually given after running [38].

\section{Exercise-dependent food-induced distress}

Gastric emptying is proportionally slowed as the concentration of carbohydrates increases in replacement fluid because of hyperosmolar effects [2].
Current nutritional recommendations to endurance athletes are generally based on advice to: 1) drink during exercise to prevent excessive dehydration and excessive changes in electrolyte balance and; 2) maintain carbohydrate oxidation rates and plasma glucose concentrations. However, these two aims (fluid delivery and carbohydrate delivery) can be difficult to reconcile as increasing the $\mathrm{CHO}$ content of a beverage to high levels increases the $\mathrm{CHO}$ delivery rate, but decreases fluid delivery. As a compromise between $\mathrm{CHO}$ and fluid delivery, it is often recommended that sports drinks have $\mathrm{CHO}$ concentrations below $8 \%$ [43].

\subsection{Hyponatremia}

Electrolyte imbalance which is commonly referred to as "water intoxication" and results from hyponatremia (low plasma sodium) due to excessive water intake has occasionally been reported in long-distance triathletes [47]. The symptoms of hyponatremia are similar to those associated with dehydration and include mental confusion, weakness and fainting. Such symptoms are usually seen at serum sodium concentrations of $126-130 \mathrm{mmol} /$ L. Below $126 \mathrm{mmol} / \mathrm{L}$, seizures, coma and death may occur [8].

Because the symptoms of hyponatremia are so similar to those of dehydration, that condition may be dangerously misdiagnosed in endurance races athletes. The usual treatment for dehydration is oral and intravenous administration of fluids. If such treatment were to be given to a hyponatremic individual, the consequences could be fatal [8].

Hyponatremia may occur in a state of euhydration or even dehydration, but it is generally associated with fluid overload [47] and the cause is the fluid intake higher than sweat rate, that causes dilutional hyponatraemia [48]. Triathletes may often develop hyponatremia without displaying symptoms [8].

In order to prevent hyponatremia, avoiding overhydration and informing athletes about the potential dangers of drinking too much water are recommended. When compared with water, a sodium-containing drink attenuated the drop in plasma sodium [49]. However, when salt tablets $(700 \mathrm{mg} / \mathrm{h})$ were given to ironmen-distance triathletes, there was no evidence that sodium intake significantly influenced changes in plasma sodium concentration or plasma volume more than did fluid replacement alone [50].

\section{Conclusions}

Physiological adaptations to physical exercises lead to blood volume redistribution favoring the working muscle supply with oxygen and energy-yielding substrate as well as the skin for heating dissipation as sweat. Strenuous exercise and/or hot-humid environments precipitate 
body dehydration, which may induce core hyperthermia, muscle glycogen depletion, gastric emptying delay, gut underperfusion (and ischemia) followed by endotoxemia or anaphylaxis. Rapid fluid delivery from fluids intake is the goal of oral rehydration solutions and sports drinks, that provide the addition of sodium and carbohydrates to assist the intestinal absorption of water and muscleglycogen replenishment, respectively. However, sometimes, fluid delivery and carbohydrate delivery are difficult to reconcile as carbohydrate-rich beverages decrease fluid delivery to the gut, thus delaying water absorption and accentuating gut underperfusion. It is necessary to inform athletes about potential dangers of drinking too much water, advise them to refrain from using hypertonic fluid replacements.

\section{Nutritional Recommendations}

- During intense exercise, is recommended an intake of $0,5 \mathrm{~L} /$ hour of sports beverages.

- A $\mathrm{CHO}(<10 \%)$ and sodium beverage should be encouraged.

- To increase the CHO exogenous oxidation, glucose plus fructose should be consumed.

\section{Author details}

${ }^{1}$ Centre for Physical Exercise and Nutrition Metabolism, UNESP School of Medicine, Public Health Department, Botucatu City, São Paulo State, Brazil. ${ }^{2}$ Department of Pathology, UNESP School of Medicine, Brazil.

\section{Authors' contributions}

EPO wrote the manuscript, revised it and approved the final version of the manuscript. RCB wrote, read and approved the final version of the manuscript.

\section{Competing interests}

The authors declare that they have no competing interests.

Received: 6 October 2010 Accepted: 28 September 2011

Published: 28 September 2011

\section{References}

1. Burini FHP, de Oliveira EP, Burini RC: Metabolic (Mal) Adaptations to Training Continuum-Misconceptions of Terminology and Diagnosis. Rev Bras Med Esporte 2010, 16:388-392.

2. Wittbrodt ET: Maintaining fluid and electrolyte balance during exercise. Journal of Pharmacy Practice 2003, 16:45-50.

3. de Oliveira EP, Burini RC: The impact of physical exercise on the gastrointestinal tract. Curr Opin Clin Nutr Metab Care 2009, 12:533-538.

4. Choi JH, Lee HB, Ahn IS, Park CW, Lee CH: Wheat-dependent, Exerciseinduced Anaphylaxis: A Successful Case of Prevention with Ketotifen. Ann Dermatol 2009, 21:203-205.

5. Fujii H, Kambe N, Fujisawa A, Kohno K, Morita E, Miyachi Y: Fooddependent exercise-induced anaphylaxis induced by low dose aspirin therapy. Allergol Int 2008, 57:97-98.

6. Rehrer NJ, Brouns F, Beckers EJ, Frey WO, Villiger B, Riddoch CJ, Menheere PP, Saris WH: Physiological changes and gastro-intestinal symptoms as a result of ultra-endurance running. Eur J Appl Physiol Occup Physiol 1992, 64:1-8.

7. Qamar MI, Read AE: Effects of exercise on mesenteric blood flow in man. Gut 1987, 28:583-587.
8. Jeukendrup $A E$, Jentjens RL, Moseley L: Nutritional considerations in triathlon. Sports Med 2005, 35:163-181.

9. Jeukendrup AE, Vet-Joop K, Sturk A, Stegen JH, Senden J, Saris WH, Wagenmakers AJ: Relationship between gastro-intestinal complaints and endotoxaemia, cytokine release and the acute-phase reaction during and after a long-distance triathlon in highly trained men. Clin Sci (Lond) 2000, 98:47-55.

10. Rehrer NJ, van Kemenade M, Meester W, Brouns F, Saris WH: Gastrointestinal complaints in relation to dietary intake in triathletes. Int J Sport Nutr 1992, 2:48-59.

11. Oktedalen O, Lunde OC, Opstad PK, Aabakken L, Kvernebo K: Changes in the gastrointestinal mucosa after long-distance running. Scand J Gastroenterol 1992, 27:270-274.

12. Shadick NA, Liang MH, Partridge AJ, Bingham C, Wright E, Fossel AH, Sheffer AL: The natural history of exercise-induced anaphylaxis: survey results from a 10-year follow-up study. J Allergy Clin Immunol 1999, 104:123-127.

13. Castells MC, Horan RF, Sheffer AL: Exercise-induced Anaphylaxis. Curr Allergy Asthma Rep 2003, 3:15-21.

14. Loibl M, Schwarz S, Ring J, Halle M, Brockow K: Definition of an exercise intensity threshold in a challenge test to diagnose food-dependent exercise-induced anaphylaxis. Allergy 2009, 64:1560-1561.

15. Orhan F, Karakas T: Food-dependent exercise-induced anaphylaxis to lentil and anaphylaxis to chickpea in a 17-year-old boy. J Investig Allergol Clin Immunol 2008, 18:465-468.

16. Morita E, Matsuo H, Chinuki Y, Takahashi H, Dahlstrom J, Tanaka A: Fooddependent exercise-induced anaphylaxis -importance of omega-5 gliadin and HMW-glutenin as causative antigens for wheat-dependent exercise-induced anaphylaxis. Allergol Int 2009, 58:493-498.

17. Bito T, Kanda E, Tanaka M, Fukunaga A, Horikawa T, Nishigori C: Cows milkdependent exercise-induced anaphylaxis under the condition of a premenstrual or ovulatory phase following skin sensitization. Allergol Int 2008, 57:437-439.

18. Barg W, Wolanczyk-Medrala A, Obojski A, Wytrychowski K, Panaszek B, Medrala W: Food-dependent exercise-induced anaphylaxis: possible impact of increased basophil histamine releasability in hyperosmolar conditions. J Investig Allergol Clin Immunol 2008, 18:312-315.

19. Castells MC, Horan RF, Sheffer AL: Exercise-induced anaphylaxis (EIA). Clin Rev Allergy Immunol 1999, 17:413-424.

20. Kato $Y$, Nagai A, Saito M, Ito T, Koga M, Tsuboi R: Food-dependent exercise-induced anaphylaxis with a high level of plasma noradrenaline. J Dermatol 2007, 34:110-113.

21. Porcel S, Sanchez AB, Rodriguez E, Fletes C, Alvarado M, Jimenez S, Hernandez J: Food-dependent exercise-induced anaphylaxis to pistachio. J Investig Allergol Clin Immunol 2006, 16:71-73.

22. Galbo H: The hormonal response to exercise. Proc Nutr Soc 1985, 44:257-266.

23. Climatic heat stress and the exercising child and adolescent. American Academy of Pediatrics. Committee on Sports Medicine and Fitness. Pediatrics 2000, 106:158-159.

24. Maresh CM, Gabaree-Boulant $C L$, Armstrong LE, Judelson DA, Hoffman JR, Castellani JW, Kenefick RW, Bergeron MF, Casa DJ: Effect of hydration status on thirst, drinking, and related hormonal responses during lowintensity exercise in the heat. J Appl Physiol 2004, 97:39-44.

25. Coris EE, Ramirez AM, Van Durme DJ: Heat illness in athletes: the dangerous combination of heat, humidity and exercise. Sports Med 2004, 34:9-16.

26. Evans GH, Shirreffs SM, Maughan RJ: Postexercise rehydration in man: the effects of carbohydrate content and osmolality of drinks ingested ad libitum. Appl Physiol Nutr Metab 2009, 34:785-793.

27. Casa DJ, Armstrong LE, Hillman SK, Montain SJ, Reiff RV, Rich BS, Roberts WO, Stone JA: National Athletic Trainers' Association Position Statement: Fluid Replacement for Athletes. J Athl Train 2000, 35:212-224.

28. Convertino VA, Armstrong LE, Coyle EF, Mack GW, Sawka MN, Senay LC Jr, Sherman WM: American College of Sports Medicine position stand. Exercise and fluid replacement. Med Sci Sports Exerc 1996, 28:i-vii.

29. Bouchama A, Knochel JP: Heat stroke. N Engl J Med 2002, 346:1978-1988.

30. van Nieuwenhoven MA, Vriens BE, Brummer RJ, Brouns F: Effect of dehydration on gastrointestinal function at rest and during exercise in humans. Eur J Appl Physiol 2000, 83:578-584. 
31. Do KD, Bellabarba C, Bhananker SM: Exertional rhabdomyolysis in a bodybuilder following overexertion: a possible link to creatine overconsumption. Clin J Sport Med 2007, 17:78-79.

32. Groeneveld GJ, Beijer C, Veldink JH, Kalmijn S, Wokke JH, van den Berg LH: Few adverse effects of long-term creatine supplementation in a placebo-controlled trial. Int J Sports Med 2005, 26:307-313.

33. Gualano B, Ugrinowitsch C, Novaes RB, Artioli GG, Shimizu MH, Seguro AC Harris RC, Lancha AH Jr: Effects of creatine supplementation on renal function: a randomized, double-blind, placebo-controlled clinical trial. Eur J Appl Physiol 2008, 103:33-40.

34. Leiper JB, Broad NP, Maughan RJ: Effect of intermittent high-intensity exercise on gastric emptying in man. Med Sci Sports Exerc 2001, 33:1270-1278.

35. Rehrer NJ, Beckers EJ, Brouns F, ten Hoor F, Saris WH: Effects of dehydration on gastric emptying and gastrointestinal distress while running. Med Sci Sports Exerc 1990, 22:790-795.

36. van Deventer S, Gouma D: Bacterial translocation and endotoxin transmigration in intestinal ischaemia and reperfusion. Curr Opinion Aneasth 1994, 7:126-130.

37. Brock-Utne JG, Gaffin SL, Wells MT, Gathiram P, Sohar E, James MF, Morrell DF, Norman RJ: Endotoxaemia in exhausted runners after a longdistance race. S Afr Med J 1988, 73:533-536.

38. Casey E, Mistry DJ, MacKnight JM: Training room management of medical conditions: sports gastroenterology. Clin Sports Med 2005, 24:525-540, viii.

39. Wright H, Collins M, Schwellnus MP: Gastrointestinal (GIT) symptoms in athletes: A review of risk factors associated with the development of GIT symptoms during exercise. International SportMed Journal 2009, 10.

40. Jeukendrup AE, Currell K, Clarke J, Cole J, Blannin AK: Effect of beverage glucose and sodium content on fluid delivery. Nutr Metab (Lond) 2009, 6:9.

41. Backx K, van Someren KA, Palmer GS: One hour cycling performance is not affected by ingested fluid volume. Int I Sport Nutr Exerc Metab 2003, 13:333-342.

42. Robinson TA, Hawley JA, Palmer GS, Wilson GR, Gray DA, Noakes TD, Dennis SC: Water ingestion does not improve 1-h cycling performance in moderate ambient temperatures. Eur J Appl Physiol Occup Physiol 1995, 71:153-160.

43. Jeukendrup AE, Moseley L: Multiple transportable carbohydrates enhance gastric emptying and fluid delivery. Scand J Med Sci Sports 2010, 20:112-121.

44. Gisolfi CV, Summers RW, Lambert GP, Xia T: Effect of beverage osmolality on intestinal fluid absorption during exercise. J Appl Physiol 1998, 85:1941-1948

45. Wallis GA, Rowlands DS, Shaw C, Jentjens RL, Jeukendrup AE: Oxidation of combined ingestion of maltodextrins and fructose during exercise. Med Sci Sports Exerc 2005, 37:426-432.

46. Ryan AJ, Lambert GP, Shi X, Chang RT, Summers RW, Gisolfi CV: Effect of hypohydration on gastric emptying and intestinal absorption during exercise. J Appl Physiol 1998, 84:1581-1588.

47. Speedy DB, Rogers IR, Noakes TD, Wright $S$, Thompson JM, Campbell R, Hellemans I, Kimber NE, Boswell DR, Kuttner JA, Safih S: Exercise-induced hyponatremia in ultradistance triathletes is caused by inappropriate fluid retention. Clin J Sport Med 2000, 10:272-278.

48. Epstein Y, Cohen-Sivan Y: Exercise-associated hyponatraemia: facts and myths. Br J Sports Med 2007, 41:111-113, author reply 111.

49. Vrijens DM, Rehrer NJ: Sodium-free fluid ingestion decreases plasma sodium during exercise in the heat. J Appl Physiol 1999, 86:1847-1851.

50. Speedy DB, Thompson JM, Rodgers I, Collins M, Sharwood K, Noakes TD: Oral salt supplementation during ultradistance exercise. Clin I Sport Med 2002, 12:279-284.

doi:10.1186/1550-2783-8-12

Cite this article as: de Oliveira and Burini: Food-dependent, exerciseinduced gastrointestinal distress. Journal of the International Society of Sports Nutrition 2011 8:12.

\section{Submit your next manuscript to BioMed Central and take full advantage of:}

- Convenient online submission

- Thorough peer review

- No space constraints or color figure charges

- Immediate publication on acceptance

- Inclusion in PubMed, CAS, Scopus and Google Scholar

- Research which is freely available for redistribution 